\title{
Audit of Clinical Care for Women with Preeclampsia or Eclampsia and Perinatal Outcome in Ethiopia: Second National EmONC Survey
}

\author{
Maereg Wagnew Meazaw ${ }^{1,2}$, Catherine Chojenta $\mathbb{D}^{2}$, Tefera Taddele ${ }^{3}$, Deborah Loxton ${ }^{2}$ \\ 'Maternal and Child Health Directorate, Federal Ministry of Health, Addis Ababa, Ethiopia; ${ }^{2}$ Centre for Women's Health Research, School of Medicine \\ and Public Health, College of Health, Medicine and Wellbeing, University of Newcastle, Newcastle, Australia; ${ }^{3}$ Health System and Reproductive Health \\ Directorate, The Ethiopian Public Health Institute, Addis Ababa, Ethiopia
}

Correspondence: Maereg Wagnew Meazaw, The University of Newcastle, University Drive, Callaghan, NSW, 2308, Australia, Tel +61402290013 , Email mulemar12@gmail.com

Background: Preeclampsia and eclampsia contribute to maternal and perinatal morbidity and mortality, especially in developing countries. However, the evidence on clinical practice in the management of preeclampsia/eclampsia and perinatal outcomes is limited. Therefore, the aim of this study was to assess clinical care and perinatal outcomes for women with preeclampsia/eclampsia admitted to health facilities in Ethiopia.

Methods: This study used the 2016 Emergency Obstetric and Newborn Care survey, which included 3804 health facilities. The last two cases of women with preeclampsia/eclampsia who were admitted for birth in each participating health facility were selected and their medical records were reviewed. Descriptive analyses by health facility type, location and management authority were conducted. A chi-squared test was used to test for differences.

Results: Out of the 3804 health-care facilities across the country, we could review a total of 959 medical records of women with preeclampsia or eclampsia. Of all cases, 90\% (863) were hospitalised in public health facilities, $542(56.6 \%)$ were admitted at health centre/clinics and $638(66.3 \%)$ were in urban health facilities. A substantial proportion of maternal and newborn information was missing from their medical records. Of the 553 records that recorded perinatal outcomes, the proportion of perinatal mortality prior to discharge was $16.3 \%$ (95\% CI: 13.4\%, 19.6\%). A significant perinatal death was recorded among mothers admitted to hospitals $(\mathrm{P}<$ 0.01), maternal age 15-24 ( $\mathrm{P}<0.04)$, facilities in urban areas $(\mathrm{P}<0.01)$, referred cases $(\mathrm{P}<0.007)$, high systolic and diastolic blood pressure $(\mathrm{P}<0.001)$, unconscious and experience seizure $(\mathrm{P}<0.001)$, newborn with morbidity $(\mathrm{P}<0.001)$, and women who spent more hours before giving birth $(\mathrm{P}<0.002)$.

Conclusions and Recommendations: High perinatal mortality in health facilities was reported and care toward mothers with preeclampsia/eclampsia was limited. Strengthening the health facility readiness to respond for management with data registration and reporting system needs to be improved for evidence-based decision-making on perinatal and maternal health.

Keywords: preeclampsia, eclampsia, perinatal mortality, Ethiopia, EmONC

\section{Introduction}

Globally, in 2017, over 295,000 women died during or following pregnancy and childbirth. ${ }^{1}$ Disproportionately, $94 \%$ of preventable pregnancy- and childbirth-related maternal deaths happened in low- and middle-income countries (LMICs), including sub-Saharan African countries. ${ }^{1,2}$ Preeclampsia and eclampsia are among the leading causes of maternal and neonatal morbidity and mortality worldwide, with the highest burden in developing countries. ${ }^{3}$ An analysis of the World Health Organization (WHO) multi-country survey has shown that there was between a 3- and 5-fold increased risk of perinatal death in women with preeclampsia and eclampsia, respectively, compared to women who did not experience these conditions. ${ }^{4}$

Ethiopia has achieved many of the Millennium Development Goals (MDGs); however, compared to other developing countries, the country still lags behind on most indicators that address maternal and neonatal health services. ${ }^{5}$ According 
to United Nations (UN) estimates, Ethiopia has reduced maternal mortality by $72 \%$ since 1990 , with a $5 \%$ annual rate of reduction. ${ }^{3}$ However, the rates of maternal and neonatal mortality are still unacceptably high compared to other countries, with 412 deaths per 100,000 live births and 29 per 1000 live births, respectively. ${ }^{6}$ Furthermore, risk of perinatal mortality (both stillbirth and early neonatal death) is particularly related to maternal conditions during pregnancy and intrapartum conditions and the rate reflects the quality of delivery care. The rate of perinatal mortality in Ethiopia is among the highest in the world, with a rate of 33 deaths per 1000 births. Based on previous studies, preeclampsia or eclampsia might contribute to as much as $25 \%$ of all stillbirths and neonatal deaths. ${ }^{7}$ In a five year retrospective review of perinatal outcomes at three teaching hospitals in southern Ethiopia, it was reported that preeclampsia contributed to a perinatal mortality rate of 290 per 1000 births. $^{8}$

To date, the underlying causes of preeclampsia and eclampsia are largely unknown and there are no wellestablished measures for primary prevention. Birth of the newborn remains the ultimate treatment. ${ }^{9}$ Access to prenatal care, early detection of the disorder, careful monitoring and appropriate management are crucial elements in the prevention of preeclampsia- and eclampsia-related morbidity and deaths. Proper management and close followup are important in women with preeclampsia/eclampsia to prevent end organ damage and serious health outcome to the mother as well as fetus. ${ }^{10-12}$ Based on WHO recommendations, women with preeclampsia and eclampsia need very close monitoring when admitted to health-care facilities due to the progressive nature of the disease and the worsening of the woman's condition if not appropriately treated. ${ }^{13}$ Although preeclampsia- and eclampsia-related morbidity and mortality has considerably fallen in developed countries, this decline has not yet been observed in developing countries. ${ }^{14,15}$ Low implementation of early detection procedures and limited access to adequate treatment might contribute to high morbidity, stillbirths and deaths among neonates born to women with preeclampsia or eclampsia. ${ }^{16}$ Hence, identifying challenges related to clinical practice in the monitoring of women with preeclampsia or eclampsia and their perinatal outcomes could provide vital evidence to help policy designers develop systems to help achieve the Sustainable Developmental Goals (SDGs) by 2030. In Ethiopia, the government initiative in expanding health facilities and access to health-care services has a vital role in improvement to maternal and neonatal care services in last decade. ${ }^{17}$ As preeclampsia/eclampsia remain the main cause of maternal mortality and morbidity in Ethiopia, there has been little research focused on the capacity of health facilities in providing quality health-care services to women with preeclampsia/eclampsia. Therefore, the aim of this study is to assess the health facilities clinical care practice in preeclampsia/eclampsia management process and identify gaps in women admitted to health facilities.

\section{Method}

\section{Study Area and Design}

The 2016 Emergency Obstetric and Newborn Care (EmONC) assessment was a national, cross-sectional census of the public and private health facilities that provided maternal and newborn health services in Ethiopia. The 2016 EmONC was the second assessment conducted, the first being in 2008. The EmONC survey collects various data on maternal and neonatal health indicators from health facility logbooks, registers and client medical records. These data have been used for policymaking and strategy development. ${ }^{18}$

\section{Data Source and Study Period}

The 2016 EmONC assessment included data from 3804 health facilities across the country. All eligible public hospitals, health centres, and eligible private (for-profit and not-for-profit) facilities (hospitals, Maternal and Child Health (MCH) Specialty Centres, MCH Specialty Clinics, and Higher Clinics) were included in the study. During the year of data collection, 4587 health facilities were to be surveyed. However, during the actual data collection, different events such as a lack of delivery services at some sites, downgrading of services, and non-functional health facilities, not all health facilities were included in the survey. The data collection period was from May to October 2016. The Ethiopia Public Health Institute (EPHI), in collaboration with the Averting Maternal Death and Disability program (AMDD), conducted the EmONC data collection. 


\section{Inclusion Criteria}

Eligibility of health facilities was determined by three characteristics: they were classified as higher clinic or above; they reported providing birthing services in the last 12 months; and they were considered functional at the time of data collection. According to the Food, Medicine and Health Care Administration and Control Authority of Ethiopia (FMHACA), all health facilities (both public and private) above health centres are eligible to provide services to birthing mothers, to attend deliveries and to treat women with preeclampsia or eclampsia. ${ }^{19}$

\section{Data Collection Instrument}

The 2016 EmONC assessment tool used 14 facility-based modules and additional modules for woreda, zone, regional, and national levels of the health system. The assessment modules were adapted from the 2008 modules, and a set of tools revised by the AMDD program of Columbia University in 2014. The data collection instruments were revised and adapted to the local context and pretested in three rounds at different health facilities prior to data collection. A more detailed description of the methods can be found in the final report. ${ }^{20}$

\section{Study Participants}

Information related to women with preeclampsia and eclampsia was collected using Module 9A under case review. Per facility, the last two cases of women diagnosed with preeclampsia or eclampsia that were admitted to the health facility in the 12 months prior to the time of data collection were selected for further review. The 12-month time period covered the 2015 calendar (January to December). Medical records and health facility registers were assessed to gather information about the women with preeclampsia and eclampsia. During the data collection, preeclampsia and eclampsia were not separately collected or reported. Therefore, throughout this study, cases are reported as "preeclampsia/eclampsia".

\section{Data Analysis}

Descriptive statistics were used for analysis. Cross tabulation and summarization of the findings of variables by type of health facility (health centre/hospitals), their location (urban or rural) and management authority (public/government, private for profit and private for non-profit) was conducted. All statistical analyses were conducted using Stata version 16. A chi-squared test was used to test for differences in treatment received and monitoring of women with preeclampsia/ eclampsia admitted to health facility by perinatal outcome. These categories were based on the FMHACA designation of health facility and those facilities with similar management mechanisms and service packages are grouped together.

\section{Ethical Clearance}

The 2016 EmONC assessment was granted ethical approval by the EPHI's scientific and ethical review board. Ethical approval was granted (approval number SERO-67-6- 2016; Version 001). A protocol was developed to conduct this analysis of the 2016 EmONC assessment dataset and received ethical approval from the EPHI scientific and ethical review board after completing the necessary procedures (Protocol number: EPHI-IRB-193-2019). In addition, ethical approval for this analysis was obtained from the University of Newcastle's Human Research Ethics Committee (approval number: H-2019-0229).

\section{Results}

\section{Background Characteristics of Women with Preeclampsia/Eclampsia}

In the 2016 EmONC survey, 959 preeclampsia/eclampsia cases were identified during the data collection period with further information collected from patient medical records. As shown in Table 1, most of the women with preeclampsia/ eclampsia received care at health centres $(55.8 \%)$ followed by primary hospitals $(19.4 \%)$. Whereas, two-thirds of women received treatment in urban health facilities $(66.5 \%)$. The vast majority of women visited a public/government health facility $(90 \%)$ compared to private for-profit $(6.3 \%)$ or private non-profit $(3.8 \%)$ facilities. The majority of the cases were reported from the three biggest regions: Oromia (32.3\%), Amhara (26.2\%) and Tigray (13.6\%). The mean maternal age was 25.3 years with Standard Deviation $(\mathrm{SD}) \pm 5.86$ with nearly half of women aged between 15 and 24 years, and 
Table I Characteristics of Women with Preeclampsia or Eclampsia in Ethiopia, National EmONC Survey, 2016

\begin{tabular}{|c|c|}
\hline Variable $(\mathrm{N}=959)$ & n (\%) \\
\hline \multicolumn{2}{|l|}{ Facility address } \\
\hline Urban & $638(66.5)$ \\
\hline Rural & $321(33.5)$ \\
\hline \multicolumn{2}{|l|}{ Type of facility } \\
\hline Hospital/MCH speciality centre & $417(43.5)$ \\
\hline Health centres/clinics & $542(56.5)$ \\
\hline \multicolumn{2}{|l|}{ Facility managing authority } \\
\hline Public/government & $863(90.0)$ \\
\hline Private for profit & $60(6.2)$ \\
\hline Private not for profit & $36(3.8)$ \\
\hline \multicolumn{2}{|l|}{ Region of health facility } \\
\hline Addis Ababa & $77(8.0)$ \\
\hline Afar & $14(\mathrm{I} .4)$ \\
\hline Amhara & $251(26.6)$ \\
\hline Benshangul Gumz & $6(0.6)$ \\
\hline Dire Dawa & $35(3.6)$ \\
\hline Gambella & $5(0.5)$ \\
\hline Harari & $12(1.2)$ \\
\hline Oramia & $309(32.2)$ \\
\hline SNNPR & $81(8.4)$ \\
\hline Somalia & $39(4.0)$ \\
\hline Tigray & $130(13.6)$ \\
\hline \multicolumn{2}{|l|}{ Age (years) } \\
\hline $15-24$ & $435(45.3)$ \\
\hline $25-34$ & $410(42.7)$ \\
\hline$\geq 35$ & $90(9.3)$ \\
\hline No information & $24(2.7)$ \\
\hline Age, mean (SD) & 25.3 years $( \pm 5.86)$ \\
\hline \multicolumn{2}{|l|}{ Parity } \\
\hline Nulliparous & $431(44.8)$ \\
\hline Primiparous & $133(13.9)$ \\
\hline Multiparous & $249(26)$ \\
\hline No information & $145(15.2)$ \\
\hline \multicolumn{2}{|l|}{ Previous maternal complications } \\
\hline No information & $622(64.9)$ \\
\hline History of previous pregnancy related complications ${ }^{a}$ & $88(9.2)$ \\
\hline First pregnancy & $249(26.0)$ \\
\hline
\end{tabular}

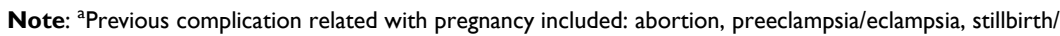
early neonatal death, diabetes mellitus.

women aged less than or equal to 18 years accounted for $10.1 \%$ of cases. Nulliparous, primiparous and multiparous mothers accounted for $44.8 \%, 13.9 \%$ and $26.0 \%$ of cases, respectively. Previous maternal complications were documented among $9.2 \%$ of women and included: stillbirth or early neonatal death (2.6\%), any preeclampsia/eclampsia history (2.2\%), and abortion (2.5\%). However, nearly two-thirds (64.8\%) of cases had incomplete or missing maternal complication histories in their medical records (see Table 1).

\section{Assessment of Clinical Condition of Women with Preeclampsia/Eclampsia During} Admission

Table 2 presents the findings describing the clinical assessments conducted with women with preeclampsia/eclampsia during admission to a health facility. Overall, women referral history only registered in $19 \%$ cases. Among the cases that 
were referred, $40 \%$ of cases were admitted to hospitals and $\mathrm{MCH}$ speciality centres, and a higher proportion (23.3\%) were admitted to private for-profit managed health facilities. More than $85 \%$ of women with preeclampsia/eclampsia had their both systolic and diastolic blood pressure measurement recorded during their admission. Whereas, compared to blood pressure, a low proportion of women had respiratory and pulse rate measurements recorded. Among the registered consciousness status upon arrival to health facilities, fifteen percent of women were unconscious during admission and the majority of them had a birth and were treated in public health facilities. Likewise, $18.1 \%$ of women experienced a seizure. Most of the information about the condition of women after admission to health facilities was not documented in the medical chart, leading to a high level of missing information. A higher proportion of missing information occurred in health centres/clinics, rural and public/government managed health facilities compared to that of hospitals, urban and private for profit or non-profit health facilities.

\section{Treatment Received at Health Facilities Among Women with Preeclampsia/Eclampsia}

Among the women who were admitted, a proteinuria test was registered for $43.5 \%$. Of these, more than $50 \%$ of proteinuria tests were registered in hospitals, urban and private for-profit health facilities. Analysis of MgSO4 administration revealed that only about one-third of women had registered information about received loading and maintenance dose of $\mathrm{MgSO} 4$ with more than $67.7 \%$ of reviewed cases missing out on the routine $\mathrm{MgSO}_{4}$ administration. Among the women who were admitted to health facilities, type of delivery was recorded for $62.8 \%$. Of these, $51 \%$ had a vaginal birth, while $12 \%$ had a caesarean section delivery. The majority of women who were admitted to private for profit $(67 \%)$ and private non-profit (44\%) health facilities had birth through caesarean section compared to $7 \%$ in public/government managed health facilities. Less than $20 \%$ of women had information in their medical record about tendon reflex and urine output monitoring during admission to health facilities. Across all variables, better clinical monitoring documentation was observed in hospitals, and urban and private for-profit health facilities (Table 3).

Table 4 describes the monitoring of women with preeclampsia/eclampsia in terms of length of stay, blood pressure check frequency and number of hours spent before giving birth. Based on the registered hours from admission to birth, the mean number of hours spent between admission and birth was 35\% higher in private for-profit health facilities (22 hours) while the national average was 14 hours. Women admitted to health centres and rural health facilities gave birth in a shorter time than the national average. In addition, the frequency of blood pressure measurement was much lower for women admitted to health centres and rural health facilities. The average length of stay was broadly similar across all types of health facilities except that women spent more days in private-for-profit and private-non-profit facilities (Table 4).

\section{Characteristics of Birth Outcome Among Women with Preeclampsia/Eclampsia}

Among newborns born to women with preeclampsia or eclampsia $(\mathrm{N}=959)$, nearly half $(42.3 \%)$ of the survival outcomes of newborns at discharge were not documented. Among registered newborn outcomes, 1 in 10 newborns died (either in stillbirth or early neonatal death) and about half of newborns (48.3\%) were known to be discharged from health facilities alive. In addition, about $15 \%$ of newborn from women with preeclampsia/eclampsia admitted to hospital for delivery died. The proportion of perinatal death was double in urban health facilities compared to rural facilities.

Only $13.7 \%$ of the newborns had neonatal morbidity details recorded in their medical records, however out of those with complete data, $38.9 \%$ of neonates with morbidities recorded died before discharge from health facilities. On the other hand, only $18.7 \%$ of neonates with morbidities were discharged alive from health facilities. Approximately twothirds of newborn deaths occurred at hospital/MCH speciality centres. Of the registered newborn morbidities, low birth weight was the highest reported morbidity (9.3\%). The proportion of perinatal outcomes was calculated based on 553 cases whose birth outcome was registered. Based on this, perinatal mortality (stillbirth or early neonatal death) was 16.3\% (95\% Confidence Interval (CI): 13.4\%, 19.6\%). Overall, 83.7\% (95\% CI: 80.4\%, 86.6\%) of newborns were known to be discharged from the health facility alive (see Table 5). 
Table 2 Percentage of Clinical Status of Women with Preeclampsia or Eclampsia During Admission to Health Facilities in Ethiopia, National EmONC Survey, 2016

\begin{tabular}{|c|c|c|c|c|c|c|c|c|}
\hline \multirow[t]{3}{*}{ Variables (\%) } & \multirow[t]{2}{*}{ National } & \multicolumn{2}{|c|}{ Facility Type } & \multicolumn{2}{|c|}{ Location } & \multicolumn{3}{|c|}{ Managing Authority } \\
\hline & & $\begin{array}{c}\text { Hospital/MCH } \\
\text { Speciality } \\
\text { Centre }\end{array}$ & $\begin{array}{l}\text { Health } \\
\text { Centrel } \\
\text { Clinics }\end{array}$ & Urban & Rural & $\begin{array}{c}\text { Publicl } \\
\text { Government }\end{array}$ & $\begin{array}{c}\text { Private- } \\
\text { for- } \\
\text { Profit }\end{array}$ & $\begin{array}{c}\text { Private- } \\
\text { Not } \\
\text { Profit }\end{array}$ \\
\hline & $n=959$ & $n=417$ & $n=542$ & $n=638$ & $n=321$ & $n=863$ & $n=60$ & $n=36$ \\
\hline \multicolumn{9}{|l|}{ Referral status } \\
\hline Yes & 19 & 40 & 3.3 & 26.3 & 5 & 19 & 23.3 & 16.7 \\
\hline No/no information & 81 & 60 & 96.7 & 73.7 & 95 & 81 & 76.7 & 83.3 \\
\hline \multicolumn{9}{|c|}{ Diastolic blood pressure } \\
\hline Yes & 86.4 & 98.6 & 77.1 & 90.6 & 78.2 & 85.4 & 96.7 & 94.4 \\
\hline No information & 13.6 & 1.4 & 22.9 & 9.4 & 21.8 & 14.6 & 3.3 & 5.6 \\
\hline \multicolumn{9}{|c|}{ Systolic blood pressure } \\
\hline Yes & 87.0 & 98.5 & 77.6 & 90.9 & 78.4 & 85.7 & 96.6 & 94.4 \\
\hline No information & 13.0 & 1.4 & 22.3 & 9.0 & 21.6 & 14.2 & 3.4 & 5.6 \\
\hline \multicolumn{9}{|l|}{ Pulse rate } \\
\hline Yes & 60.2 & 86.3 & 40.0 & 66.5 & 47.7 & 58.9 & 80.0 & 58.3 \\
\hline No information & 39.8 & 13.7 & 60.0 & 33.5 & 52.3 & $4 I . I$ & 20.0 & 41.7 \\
\hline \multicolumn{9}{|l|}{ Respiratory rate } \\
\hline Yes & 45.4 & 74.1 & 23.2 & 53.6 & 29 & 45.9 & 43.3 & 36.1 \\
\hline No information & 54.6 & 25.9 & 76.8 & 46.6 & 71 & 54.1 & 56.7 & 63.9 \\
\hline \multicolumn{9}{|c|}{ Consciousness status } \\
\hline Yes & 14.7 & 13.4 & 15.7 & 13.3 & 17.4 & 15.6 & 5.0 & 8.3 \\
\hline No information & 85.3 & 86.6 & 84.3 & 86.7 & 82.6 & 84.4 & 95.0 & 91.7 \\
\hline \multicolumn{9}{|l|}{ Seizure experience } \\
\hline Yes & 18.1 & 23.5 & 14.0 & 17.2 & 20.0 & 19 & 11.3 & 8.3 \\
\hline No/No information & 81.9 & 76.5 & 86.0 & 82.8 & 80.0 & 89.0 & 88.3 & 91.7 \\
\hline
\end{tabular}

\section{Characteristics of Women with Preeclampsia or Eclampsia with Perinatal Mortality} and Alive at Discharge

The monitoring and treatment characteristics of women with preeclampsia/eclampsia based on their birth outcome is summarised in Table 6. Of the registered 90 perinatal deaths among women with preeclampsia/eclampsia who were admitted to health facilities for birth, the majority of them were admitted to hospitals and urban health facilities. Almost half of perinatal deaths occurred in women age 15 to 24 (48.8\%) and first-time pregnant women (47.6\%). Perinatal deaths occurred in $9 \%$ of women who had documented previous maternal complications. Despite more than $60 \%$ of referral histories not being recorded, one-third of perinatal deaths occurred in women who were referred to a health facility for birth $(\mathrm{P}<0.007 *)$. One quarter of women with a live birth were referred from another health facility for birth. The majority of women experienced severe diastolic and systolic blood pressure had higher proportion of perinatal death compared to women with alive birth $\left(\mathrm{P}<0.001^{*}\right)$. Of the 90 women with preeclampsia/eclampsia who were identified as experiencing perinatal death, 41 (45.5\%) received the loading dose MgSO4 while the remaining 54.5\% women had no information about loading dose of MgSO4. Similarly, 39 (43.4\%) women received a maintenance dose of MgSO4. Women who experienced a perinatal death had double number of hours spent before birth of the newborn (mean=23 hours) compared to those women who were discharged with a live birth (mean=11.6 hours). A significant high proportion of newborn with registered neonatal morbidity end up to death. As a result, four out of ten newborns with morbidities such as low birth weight and birth asphyxia were not discharged from the health facility alive (Table 6). 
Table 3 Treatment Received During Admission to Health Facility Among Women with Preeclampsia/Eclampsia in Ethiopia, National EmONC Survey, 2016

\begin{tabular}{|c|c|c|c|c|c|c|c|c|}
\hline \multirow{3}{*}{ Variables,\% } & \multirow[t]{2}{*}{ National } & \multicolumn{2}{|c|}{ Facility Type } & \multicolumn{2}{|c|}{ Location } & \multicolumn{3}{|c|}{ Managing Authority } \\
\hline & & $\begin{array}{c}\text { Hospital/ } \\
\text { МСH } \\
\text { Speciality }\end{array}$ & $\begin{array}{l}\text { Health } \\
\text { Centrel } \\
\text { Clinics }\end{array}$ & Urban & Rural & $\begin{array}{l}\text { Publicl } \\
\text { Government }\end{array}$ & $\begin{array}{c}\text { Private- } \\
\text { for- } \\
\text { Profit }\end{array}$ & $\begin{array}{c}\text { Private- } \\
\text { Not for } \\
\text { Profit }\end{array}$ \\
\hline & $n=959$ & $n=417$ & $n=542$ & $n=638$ & $n=321$ & $n=863$ & $n=60$ & $n=36$ \\
\hline \multicolumn{9}{|l|}{$\begin{array}{l}\text { Proteinuria tested } \\
\text { registered }\end{array}$} \\
\hline Yes & 43.5 & 62.6 & 29.5 & 52.0 & 27.0 & 42.8 & 52.3 & 45.0 \\
\hline No & 56.5 & 38.4 & 70.5 & 48.0 & 73.0 & 57.2 & 46.7 & 55.0 \\
\hline \multicolumn{9}{|c|}{$\begin{array}{l}\text { Loading dose MgSO4 } \\
\text { given }\end{array}$} \\
\hline Yes & 33.7 & 56.0 & 16.4 & 40.8 & 19.6 & 33.7 & 27.0 & 39.0 \\
\hline No information & 66.3 & 44.0 & 83.6 & 59.2 & 80.4 & 66.3 & 7.03 & 59.0 \\
\hline \multicolumn{9}{|c|}{$\begin{array}{l}\text { Maintenance dose MgSO4 } \\
\text { given }\end{array}$} \\
\hline Yes & 29.0 & 9.5 & 3.4 & 37.5 & 22.0 & 28.5 & 30.0 & 36.0 \\
\hline No/no information & 71.0 & 40.5 & 94.6 & 62.5 & 88.0 & 71.5 & 70.0 & 64.0 \\
\hline \multicolumn{9}{|c|}{ Route of MgSO4 given } \\
\hline Intramuscular (IM) & 5.7 & 9.6 & 2.8 & 7.2 & 2.8 & 5.3 & 3.3 & 19.4 \\
\hline Intravenous (IV) & 8.3 & 13.7 & 4.1 & 9.6 & 5.6 & 8.8 & 1.7 & 5.6 \\
\hline IM\& IV & 18.3 & 32.6 & 7.4 & 22.4 & 10.3 & 19.0 & 11.7 & 13.9 \\
\hline No information & 67.7 & 44.1 & 85.8 & 60.8 & 81.3 & 66.9 & 83.3 & 61.1 \\
\hline \multicolumn{9}{|l|}{ Tendon reflexes } \\
\hline Yes & 11 & 22.5 & 1.8 & 15.3 & 2.0 & 10.0 & 13.3 & 25.0 \\
\hline No/No information & 89 & 77.5 & 98.2 & 84.6 & 98.0 & 90.0 & 86.7 & 75.0 \\
\hline \multicolumn{9}{|l|}{ Mode of birth } \\
\hline Vaginal & 50.9 & 63.0 & 42.0 & 51.0 & 51.0 & 53.0 & 27.0 & 36.0 \\
\hline Caesarean section & 12.0 & 26.0 & 1.0 & 17.0 & 2.0 & 7.0 & 67.0 & 44.0 \\
\hline No information & 37.1 & 11.0 & 57.0 & 32.0 & 47.0 & 40.0 & 7.0 & 19.0 \\
\hline \multicolumn{9}{|c|}{ Urine output monitored } \\
\hline Yes & 20.0 & 43.2 & 2.0 & 28.7 & 2.5 & 27.6 & 50.0 & 25.0 \\
\hline No/No information & 80.0 & 56.8 & 98.0 & 71.3 & 97.5 & 82.4 & 50.0 & 75.0 \\
\hline
\end{tabular}

\section{Discussion}

This study analysed data recorded for women with preeclampsia or eclampsia who were admitted for birth in Ethiopian health-care facilities. This was the first national study that evaluated the management of women with preeclampsia/ eclampsia and their newborn outcomes using a nationally representative dataset. During the analysis, we identified several services were not registered during treatment and monitoring of women with preeclampsia and eclampsia that must be corrected in order to improve maternal and foetal outcomes.

Health information is a critical element in providing health care, including maternal healthcare. This study highlighted serious gaps in the information registered at health facilities in Ethiopia, noting that a significant proportion of information was missing. The huge rate of missing information in maternal and newborn health could lead to failure in decision-making. According to the WHO framework, information is a key component of quality improvement in healthcare. ${ }^{21}$ Well-documented information is important for policy makers and managers to risks experienced by women with preeclampsia and eclampsia. Disproportionate procurement of medical commodities and supplies to health facilities results in compromised service provision, and this leads to a reduced quality of service to mothers and their newborns. In health-care systems, accurate and complete information collection and registration facilitates appropriate resourcing and 
Table 4 Descriptive Statistics of Monitoring Women with Preeclampsia/Eclampsia Based on Type, Location and Authority of Health Facility in Ethiopia, National EmONC Survey, 2016

\begin{tabular}{|c|c|c|c|c|c|c|c|c|}
\hline \multirow[t]{2}{*}{ Variables } & \multirow[t]{2}{*}{ National } & \multicolumn{2}{|l|}{ Facility type } & \multicolumn{2}{|l|}{ Location } & \multicolumn{3}{|c|}{ Managing Authority } \\
\hline & & $\begin{array}{l}\text { Hospital/MCH } \\
\text { Speciality } \\
\text { Centre }\end{array}$ & $\begin{array}{l}\text { Health } \\
\text { Centre/Clinics }\end{array}$ & Urban & Rural & $\begin{array}{l}\text { Publicl } \\
\text { Government }\end{array}$ & $\begin{array}{l}\text { Private-for- } \\
\text { Profit }\end{array}$ & $\begin{array}{l}\text { Private-Not for } \\
\text { Profit }\end{array}$ \\
\hline & & $(n=4 \mid 7)$ & $(n=542)$ & $(n=638)$ & $(n=321)$ & $(n=863)$ & $(n=60)$ & $(n=36)$ \\
\hline $\begin{array}{l}\text { Time between admission and } \\
\text { birth ( } n=265) \text { (hours) } \mu \text { (SD), } \\
\text { p50 }\end{array}$ & $14( \pm 19.9), 6$ & $16.3( \pm 21.4), 7$ & $8( \pm \mid 4.6), 5$ & $15.6( \pm 2 I), 6$ & $8.3( \pm 13.8), 5$ & $13( \pm 19.8), 6$ & $21.8( \pm 20.8), 18$ & $18.1( \pm \mid 8.2), 13.5$ \\
\hline $\begin{array}{l}\text { Number of blood pressure } \\
\text { check }(n=609) \mu(\text { SD), p50 }\end{array}$ & $13.3( \pm 16.9), 8$ & $19.5( \pm$ 18.9), I 4 & 3.9 ( \pm 5.7$), 2$ & $16.4( \pm 18.3), 12$ & 4.8 ( \pm 7.7$), 2$ & II $( \pm 14.8), 6$ & 28.7 ( \pm 25.9$), 20$ & $17( \pm 19.7), 14$ \\
\hline $\begin{array}{l}\text { Number of days hospitalized } \\
(n=394) \text {, days } \mu \text { (SD), p50 }\end{array}$ & $5.6( \pm 6.2), 4$ & $5.6( \pm 6.8), 4$ & $5.6( \pm 3.6), 8$ & $5.6( \pm 6.6), 4$ & $5.6( \pm 4.2), 5$ & $5.3( \pm 4), 4$ & $6.7( \pm \mid 3.6), 3$ & 7 ( \pm 6.9$), 5$ \\
\hline
\end{tabular}


Table 5 Characteristics of Birth Outcomes Among Women with Preeclampsia or Eclampsia in Ethiopia, National EmONC Survey, 2016

\begin{tabular}{|c|c|c|c|c|c|c|c|c|}
\hline \multirow[t]{3}{*}{ Variables, \% } & \multirow[t]{2}{*}{ National } & \multicolumn{2}{|c|}{ Facility Type } & \multicolumn{2}{|c|}{ Location } & \multicolumn{3}{|c|}{ Managing Authority } \\
\hline & & $\begin{array}{l}\text { Hospital/ } \\
\text { MCH } \\
\text { Speciality }\end{array}$ & $\begin{array}{l}\text { Health } \\
\text { Centrel } \\
\text { Clinics }\end{array}$ & Urban & Rural & $\begin{array}{l}\text { Publicl } \\
\text { Government }\end{array}$ & $\begin{array}{l}\text { Private- } \\
\text { for- } \\
\text { Profit }\end{array}$ & $\begin{array}{l}\text { Private- } \\
\text { Not for } \\
\text { Profit }\end{array}$ \\
\hline & $n=959$ & $n=417$ & $n=542$ & $n=638$ & $n=321$ & $n=863$ & $n=60$ & $n=36$ \\
\hline \multicolumn{9}{|l|}{ Newborn morbidity } \\
\hline Low birth weight & 9.7 & 16.5 & 4.4 & 11.8 & 5.6 & 9.0 & 15.0 & 16.7 \\
\hline Birth asphyxia & 2.8 & 4.3 & 1.7 & 3.0 & 2.5 & 3.1 & 0 & 0 \\
\hline$M A S^{b}$ & 0.9 & 1.9 & 0.2 & 1.3 & 0.3 & 0.8 & 3.3 & 0 \\
\hline Macrosomia & 0.3 & 0.5 & 0.2 & 0.3 & 0.3 & 0.2 & 1.7 & 0 \\
\hline No information & 86.2 & 76.5 & 93.5 & 83.5 & 91.3 & 86.7 & 80 & 83.3 \\
\hline \multicolumn{9}{|l|}{ Newborn survival } \\
\hline Alive at discharge & 48.3 & 65.5 & 35.1 & 50.3 & 44.2 & 45.9 & 71.7 & 66.7 \\
\hline Perinatal death ${ }^{c}$ & 9.4 & 15.6 & 4.6 & 11.6 & 5.0 & 9.5 & 6.7 & II.I \\
\hline No information & 42.3 & 18.9 & 60.3 & 38.1 & 50.8 & 44.6 & 21.7 & 22.2 \\
\hline
\end{tabular}

Notes: ${ }^{b}$ MAS - Meconium Aspiration Syndrome. 'Include both stillbirth and early neonatal death.

saves the lives of mothers and newborns. In a situation with limited resources, accurate record-keeping is more important for more efficient use of available resources to treat women with preeclampsia/eclampsia.

Perinatal mortality is one of the most sensitive indicators for obstetric care quality. In Ethiopia, the perinatal mortality rate was 33 deaths per 1000 births based on the 2016 Ethiopia Demographic Health Survey (EDHS) report, and this is one of the highest rates in the world. ${ }^{6}$ In this study, the proportion of perinatal mortality among women with preeclampsia or eclampsia was $16.3 \%$, which is slightly higher compared to a previous review of the contribution preeclampsia or eclampsia makes to perinatal mortality, which estimated that this disease precedes $15 \%$ of perinatal deaths worldwide. ${ }^{22}$ Similarly, small-scale studies conducted in Ethiopia at Mettu Karl hospital ${ }^{23}$ and selected hospitals in Addis $\mathrm{Ababa}^{24}$ indicated that nearly $12 \%$ of perinatal mortality was reported in women with preeclampsia or eclampsia.

Overall, among the women with referral history, majority of them were admitted at hospitals and private for-profit health facilities. This could be due to women seeking more equipped health facilities and the larger facilities having more specialists to provide advanced medical care. Importantly, the majority of vital signs check-up variables such as pulse and respiratory rate during admission were unknown or not documented. Consistent with our findings, poor documentation of women's clinical status during admission was reported in a study conducted in four sub-Saharan African countries. ${ }^{25}$ Only $20 \%$ of women had information recorded about urine output, with hospitals being more likely to monitor this important clinical indicator compared to other facilities. WHO has recommended that women with preeclampsia and eclampsia receive treatment in advanced health-care facilities. ${ }^{13}$ In Ethiopia's health-care system, hospitals provide advanced care and high risk pregnant women are encouraged to seek services in health facilities that offer comprehensive services, such as caesarean section. ${ }^{16}$ Our study also found that women admitted to hospitals were better monitored than women in health centres, and were also more likely to receive services such as administration of $\mathrm{MgSO} 4$. On the other hand, there was high perinatal morbidity and mortality reported from hospitals and urban-located health facilities compared to health facilities in rural areas and health centres. This may be due to the high rate of referral of mothers with complications to hospitals and better documentation in hospitals. There has been an expansion of health facilities, especially health centres, in rural parts of Ethiopia. ${ }^{26}$ However, increases in access alone mean little if the services provided are not of high quality. A recent Service Availability and Readiness Assessment (SARA), 2018 survey reported that health centres, especially those located in rural areas, have been faced with several challenges, such as being poorly equipped and supervised, having unsustainable running costs, and an insufficient quality of care to deliver improved 
Table 6 Characteristics of Women with Preeclampsia or Eclampsia with Perinatal Mortality and Alive at Discharge in Ethiopia, National EmONC Survey, 2016

\begin{tabular}{|c|c|c|c|}
\hline Variable & Perinatal Mortality & Alive at Discharge & P-value \\
\hline$(n=553)$ & $(n=90)$ & $(n=463)$ & \\
\hline Type of facility & & & $\mathrm{P}<0.0 \mathrm{I}^{*}$ \\
\hline Hospital/MCH specialized hospital & 72.2 & 59.0 & \\
\hline Health centre/clinic & 27.8 & 41.0 & \\
\hline Facility address & & & $P<0.016 *$ \\
\hline Urban & 82.2 & 69.3 & \\
\hline Rural & 17.8 & 30.7 & \\
\hline Facility managing authority & & & $P<0.247$ \\
\hline Public/government & 91.1 & 85.5 & \\
\hline Private for profit & 4.4 & 9.3 & \\
\hline Private not for profit & 4.4 & 5.2 & \\
\hline Age (years) $(n=548)$ & & & $P<0.045^{*}$ \\
\hline $15-24$ & 48.8 & 45.0 & \\
\hline $25-34$ & 44.3 & 44.1 & \\
\hline$\geq 35$ & 6.8 & 10.9 & \\
\hline Parity $(n=493)$ & & & $P<0.55$ \\
\hline Nulliparous & 47.6 & 53.8 & \\
\hline Primiparous & 20.7 & 17.0 & \\
\hline Multiparous & 31.7 & 29.2 & \\
\hline Previous maternal complication & & & $P<0.66$ \\
\hline Has previous pregnancy related complication & 8.9 & 10.4 & \\
\hline None/no information & 91.1 & 89.6 & \\
\hline Referred from another facility & & & $P<0.007^{*}$ \\
\hline Yes & 37.8 & 23.8 & \\
\hline No/no information & 62.2 & 76.2 & \\
\hline Systolic blood pressure $(n=499)$ & & & $P<0.00 I^{*}$ \\
\hline$<160 \mathrm{mmHg}$ & 20.2 & 43.6 & \\
\hline$\geq 160 \mathrm{mmHg}$ & 79.8 & 56.4 & \\
\hline Diastolic blood pressure $(n=499)$ & & & $\mathrm{P}<0.00 \mathrm{I}^{*}$ \\
\hline$<110 \mathrm{mmHg}$ & 30.1 & 52.8 & \\
\hline$\geq 110 \mathrm{mmHg}$ & 69.9 & 47.2 & \\
\hline Conscious & & & $P<0.00 I^{*}$ \\
\hline Not conscious & 30.0 & 9.5 & \\
\hline Conscious & 70.0 & 90.5 & \\
\hline Seizure experience & & & $P<0.042 *$ \\
\hline Yes & 27.8 & 18.1 & \\
\hline No/no information & 72.2 & 81.9 & \\
\hline Antihypertensive drug used $(n=335)$ & & & $P<0.67$ \\
\hline Hydralazine & 73.6 & 71.1 & \\
\hline Other & 26.4 & 28.9 & \\
\hline Loading dose of MgSO4 & & & $P<0.65$ \\
\hline Yes & 45.5 & 43.0 & \\
\hline No/no information & 54.4 & 57.0 & \\
\hline Maintenance dose of MgSO4 & & & $P<0.68$ \\
\hline Yes & 43.3 & 41.0 & \\
\hline No/no information & 56.7 & 59.0 & \\
\hline Proteinuria tested & & & $P<0.74$ \\
\hline Yes & 48.9 & 50.8 & \\
\hline No & 51.1 & 49.2 & \\
\hline
\end{tabular}


Table 6 (Continued).

\begin{tabular}{|c|c|c|c|}
\hline Variable & Perinatal Mortality & Alive at Discharge & \multirow[t]{2}{*}{ P-value } \\
\hline$(n=553)$ & $(n=90)$ & $(n=463)$ & \\
\hline Mode of birth $(n=5 \mid 9)$ & & & $P<0.72$ \\
\hline Caesarean section birth & 17.5 & 19.1 & \\
\hline Vaginal birth & 82.5 & 80.9 & \\
\hline Route of MgSO4 given & & & $P<0.46$ \\
\hline Intramuscular & 7.8 & 7.3 & \\
\hline Intravenous & 13.3 & 11.4 & \\
\hline IM\& IV & 28.9 & 22.5 & \\
\hline No information & 50.0 & 58.8 & \\
\hline Urine output monitored & & & $P<0.85$ \\
\hline Yes & 27.8 & 28.7 & \\
\hline No/No information & 72.2 & 71.3 & \\
\hline Newborn morbidity & & & $\mathrm{P}<0.00 I^{*}$ \\
\hline Newborn with morbidity & 39.0 & 18.4 & \\
\hline No information & 61.0 & 81.6 & \\
\hline Time spent before birth (hours) & $23( \pm 25.7), 13.5 \mathrm{hrs}$ & $11.6 \mathrm{hr}( \pm 17.2), 6 \mathrm{hrs}$ & $P<0.002 *$ \\
\hline Number of blood pressure check & $19( \pm 21.4), 13$ times & I4.5 ( \pm 16$)$, I I times & $P<0.04^{*}$ \\
\hline Number of days hospitalized & $6( \pm 4.9), 4$ days & 5 ( \pm 6.8), 3 days & $P<0.37$ \\
\hline
\end{tabular}

Note: *Statistical significant with $\mathrm{p}<0.05$.

health outcomes. ${ }^{27}$ Therefore, strengthening those segments of health-care facilities could significantly reduce the complications and mortality related with preeclampsia and eclampsia in Ethiopia.

According to the national protocol for screening and management of preeclampsia and eclampsia, pregnant women should be screened for signs and symptoms of preeclampsia and eclampsia both clinically and in laboratory tests. In this study, less than half of admitted women were tested for proteinuria and this was even less among women admitted to health centres $(29.5 \%)$ and in rural areas $(27 \%)$. This is consistent with findings from Zambia where $23 \%$ of health facilities conducted urine tests. ${ }^{28}$ The WHO recommends administration of $\mathrm{MgSO} 4$ for women diagnosed with preeclampsia or eclampsia, in order to reduce disease progress and further complications. ${ }^{13}$ In our study, again noting the high degree of missing information, a small proportion of women admitted to health centres and rural areas received both loading and maintenance doses of MgSO4. Although the majority of women with preeclampsia/eclampsia were admitted to public/government managed health facilities, snapshot evidence suggests that private for profit and not-for-profit health facilities showed a slightly better proportion in documentation than public/government managed health facilities. There might be multiple factors for the low proportion in testing and administering MgSO4 that our study was not able to distinguish. These include supply chain management issues leading to stock-outs of supplies; absence of clear, up-to-date national guidelines, and/or a lack of health worker understanding of, and compliance with, guidelines.

This study revealed a huge variation in the overall survival of newborns from women with preeclampsia and eclampsia along with the characteristics of mothers and the management received. Consistent with other studies, a significant proportion of perinatal mortality was registered among women with severe diastolic and systolic blood pressure, younger age and first-time pregnancy. ${ }^{29,30}$ In this study, mothers with perinatal deaths spent more hours in health facilities before giving birth as compared to those discharge with alive newborn. As outlined by Thaddeus and Maine ${ }^{31}$ delays in provision of adequate and timely care resulted in serious consequences for the mother and newborn. A lack of supplies and equipment, insufficient knowledge and skills health workers and poor leadership are key factors in delays of service provision in Ethiopia. ${ }^{32}$ Therefore, this study informs to decision maker about the challenges related with care to women with preeclampsia/eclampsia and quality of services in health-care facilities.

Overall, the findings from this study provide vital evidence to inform programs and policy, and to guide investment in maternal and child health to reduce complications including death, which are related to PE/E in Ethiopia. Cognisant of 
the fact that providing appropriate and standardized clinical care to women with preeclamspsia/eclampsia can significantly reduce the morbidity and mortality of mothers and the newborn. Therefore, this study provides insight into the policy makers the level of clinical care to women with preeclampsia/eclampsia and the perinatal outcome in the health facilities. In addition, the importance strengthen the information registration and recording highlighted in this study.

\section{Strengths and Limitations of the Study}

A major strength of this study is that its findings are nationally representative as cases were collected from all regions of Ethiopia. Almost all public/government health facilities that provide delivery services were included. In addition, private health facilities were included, further strengthening this study's representativeness. In addition, rigorous data collection processes were in place through the involvement of experts from national and international partners, AMDD program of Columbia University. Intensive training of data collectors, regular supervision, and continuous data quality monitoring were conducted before and during data collection.

However, this study is not without limitations. The first limitation of our study related to the design of study, crosssectional study, which cannot determine causal relationships. A second limitation is that home delivery still significantly common in Ethiopia, especially in rural part of the country; ${ }^{6}$ however, this study included only deliveries at health facilities. That is, only include women who came to health facilities to seek care and may obscure the magnitude of the problem at the community level. A third limitation is this study intended to review two cases per facility; however, during the actual data collection period, not all cases from all health facilities are not collected due to several reasons. Therefore, the result of this study must be carefully interpreted. In addition, the quality of care for newborns was not assessed, which may have contributed to high perinatal mortality. Similarly, the data collection tools lack some important indicators of perinatal outcomes, such as history of ANC visits, gestational weeks at delivery, and any interventions the newborn received during delivery. In addition, some variables mentioned as "no/no information" which not able to distinguish between the cases with no event to that particular variable and those with missing information. Furthermore, cases were not reviewed as separately collected as preeclampsia or eclampsia. Lastly, there was a high percentage of missing information due to a lack of documentation in the mother's medical records and registries; this needs to be improved in order to increase the quality of maternal and child health in Ethiopia. Despite these limitations, this study provides important evidence on gaps in management of preeclampsia/eclampsia and some insight into the newborn outcome at health facilities in Ethiopia.

\section{Conclusion}

Perinatal mortality among women with preeclampsia or eclampsia is high in Ethiopia. In addition, a significant number of neonates experience morbidity. This study highlights the notable amount of important information on women with preeclampsia or eclampsia that was missing from medical charts and logbooks. Hence, this study underscores the need for quality control and monitoring of information registration in health facilities, as accurate and complete information helps reveal the gaps in clinical practice on managing preeclampsia and related perinatal mortality and mortality. In addition, although private health facilities have a big role in service provision, a high proportion of maternal and newborn information was missing there as well. Most importantly, improving maternal and neonatal health information management is vital to generate strong evidence for policymakers. Once the pregnant women were diagnosed with preeclampsia or eclampsia, the outcome of mother and survival of newborns were largely influenced by early screening for complications, proper management and timely referral for better treatment. ${ }^{13}$ Overall, to improve the quality of management and reduce perinatal morbidity and mortality, interventions are needed to monitor women during ANC visits, identify highrisk women, and strengthen hospitals to provide quality care.

This study also indicated hospitals and health facilities located in urban areas managed a substantial number of cases compared to health centres and rural area health facilities. Furthermore, significant variation in findings on the usage of $\mathrm{MgSO} 4$ and general monitoring of admitted mothers based on types and location of health facilities indicated the importance of further investigation. However, based on our finding it is clear that there are gaps in service delivery quality in both urban/rural and hospital/health centres that could be addressed immediately to improve access to this lifesaving intervention. 


\section{Acknowledgments}

The authors would like to thank the University of Newcastle, Australia, for providing free digital access to the online library and Natalia Soeters for her assistance in language review to this document. We would also like to give thanks to the EPHI 2016 EmONC assessment team, data collectors, trainers and health facility authorities that participated in this national survey.

\section{Author Contributions}

All authors made a significant contribution to the work reported, whether that is in the conception, study design, execution, acquisition of data, analysis and interpretation, or in all these areas; took part in drafting, revising or critically reviewing the article; gave final approval of the version to be published; have agreed on the journal to which the article has been submitted; and agree to be accountable for all aspects of the work.

\section{Disclosure}

The authors report no conflicts of interest in this work.

\section{References}

1. Trends in maternal mortality: 2000 to 2017: estimates by WHO. UNICEF, UNFPA, World Bank Group and the United Nations Population Division. Geneva: World Health Organization; 2019.

2. Alkema L, Chou D, Hogan D, et al. Global, regional, and national levels and trends in maternal mortality between 1990 and 2015 , with scenario-based projections to 2030: a systematic analysis by the UN Maternal Mortality Estimation Inter-Agency Group. Lancet. 2016;387 North American Edition(10017):462-474. doi:10.1016/S0140-6736(15)00838-7

3. World Health Organization. Trends-in-maternal-mortality-1990-to-2015: estimates by WHO, UNICEF, UNFPA, World Bank Group and the United Nations Population Division; 2015.

4. Roberts JM, Pearson G, Cutler J, Lindheimer M. Summary of the NHLBI Working Group on Research on Hypertension During Pregnancy. Hypertension. 2003;41(3):437-445. doi:10.1161/01.HYP.0000054981.03589.E9

5. Assefa Y, Damme WV, Williams OD, Hill PS. Successes and challenges of the millennium development goals in Ethiopia: lessons for the sustainable development goals. BMJ Glob Health. 2017;2(2):e000318. doi:10.1136/bmjgh-2017-000318

6. Central Statistical Agency - CSA/Ethiopia, ICF. Ethiopia demographic and health survey 2016. Addis Ababa, Ethiopia: CSA and ICF; 2017.

7. Duley L. Maternal mortality associated with hypertensive disorders of pregnancy in Africa, Asia, Latin America and the Caribbean. Br J Obstet Gynaecol. 1992;99(7):547-553. doi:10.1111/j.1471-0528.1992.tb13818.x

8. Endeshaw G, Berhan Y. Perinatal outcome in women with hypertensive disorders of pregnancy: a retrospective cohort study. Int Sch Res Notices. 2015;2015:208043. doi:10.1155/2015/208043

9. Wagner LK. Diagnosis and management of preeclampsia. Am Fam Physician. 2004;70(12):2317-2324.

10. Ghulmiyyah L, Sibai B. Maternal mortality from Preeclampsia/Eclampsia. Semin Perinatol. 2012;36:56-59. doi:10.1053/j.semperi.2011.09.011

11. Belay Tolu L, Yigezu E, Urgie T, Feyissa GT. Maternal and perinatal outcome of preeclampsia without severe feature among pregnant women managed at a tertiary referral hospital in urban Ethiopia. PLoS One. 2020;15(4):e0230638. doi:10.1371/journal.pone.0230638

12. Mayrink J, Costa ML, Cecatti JG. Preeclampsia in 2018: revisiting concepts, physiopathology, and prediction. Sci World J. 2018;2018:6268276. doi: $10.1155 / 2018 / 6268276$

13. World Health Organization. WHO recommendations for prevention and treatment of pre-eclampsia and eclampsia. Geneva; 2011.

14. Onuh SO, Aisien AO. Maternal and fetal outcome in eclamptic patients in Benin City, Nigeria. J Obstet Gynaecol. 2004;24(7):765-768. doi:10.1080/01443610400009451

15. Berhan Y, Berhan A. Causes of maternal mortality in Ethiopia: a significant decline in abortion related death. Ethiop. 2014;24:15-28.

16. FDRE Ministry of Health (FMoH). Health Sector Transformation Plan (HSTP) 2015/16-2019/20. Addis Ababa, Ethiopia; 2020.

17. Croke K, Telaye Mengistu A, O'Connell SD, Tafere K. The impact of a health facility construction campaign on health service utilisation and outcomes: analysis of spatially linked survey and facility location data in Ethiopia. BMJ Global Health. 2020;5(8):e002430. doi:10.1136/bmjgh2020-002430

18. Gaym A, Bailey P, Pearson L, Admasu K, Gebrehiwot Y. Disease burden due to pre-eclampsia/eclampsia and the Ethiopian health system's response. Int J GynecolObstet. 2011;115(1):112-116. doi:10.1016/j.ijgo.2011.07.012

19. Ethiopian Food MaHAaCA. Health center - requirements. Addis Ababa; 2012.

20. Ministry of Health. Ethiopian Emergency Obstetric and Newborn Care (EmONC) Assessment 2016 - Final Report; 2017.

21. World Health Organization. Quality of care: a process for making strategic choices in health systems. Geneva: World Health Organization; 2006.

22. von Dadelszen P, Magee LA. Preventing deaths due to the hypertensive disorders of pregnancy. Best Pract Res Clin Obstet Gynaecol. 2016;36:83-102. doi:10.1016/j.bpobgyn.2016.05.005

23. Seyom E, Abera M, Tesfaye M, Fentahun N. Maternal and fetal outcome of pregnancy related hypertension in Mettu Karl Referral Hospital, Ethiopia. J Ovarian Res. 2015;8:10. doi:10.1186/s13048-015-0135-5

24. Wagnew M, Dessalegn M, Worku A, Nyagero J. Trends of preeclampsia/eclampsia and maternal and neonatal outcomes among women delivering in Addis Ababa selected government hospitals, Ethiopia: a retrospective cross-sectional study. Pan Afr Med J. 2016;25(Suppl 2):12. doi:10.11604/ pamj.supp.2016.25.2.9716 
25. Rawlins B, Plotkin M, Rakotovao JP, et al. Screening and management of pre-eclampsia and eclampsia in antenatal and labor and delivery services: findings from cross-sectional observation studies in six sub-Saharan African countries. BMC Pregnancy Childbirth. 2018;18(1):346. doi:10.1186/ s12884-018-1972-1

26. FDRE Ministry of Health (FMoH). Health Sector Transformation Plan (HSTP) 2015/16-2019/20. Addis Ababa, Ethiopia; 2015.

27. Theodros ZG. Service Availability and Readiness Assessment (SARA); 2018.

28. Miyoshi Y, Matsubara K, Takata N, Oka Y. Perinatal care for Zambian pregnant women complicated with preeclampsia: the medication rooted in the region to stabilize its local management in zimba. Pregnancy Hypertens. 2018;13:S52. doi:10.1016/j.preghy.2018.08.155

29. Meazaw MW, Chojenta C, Muluneh MD, Loxton D. Systematic and meta-analysis of factors associated with preeclampsia and eclampsia in sub-Saharan Africa. PLoS One. 2020;15(8):e0237600. doi:10.1371/journal.pone.0237600

30. Anorlu RI, Iwuala NC, Odum CU. Risk factors for pre-eclampsia in Lagos, Nigeria. Aust N Z J Obstet Gynaecol. 2005;45(4):278-282. doi:10.1111/ j.1479-828X.2005.00411.x

31. Thaddeus S, Maine D. Too far to walk: maternal mortality in context. Soc Sci Med. 1994;38(8):1091-1110. doi:10.1016/0277-9536(94)90226-7

32. Berhan Y, Berhan A. Commentary: reasons for persistently high maternal and perinatal mortalities in Ethiopia: part III-Perspective of the "three delays" model. Ethiop. 2014;24 Suppl(0 Suppl):137-148.

\section{Publish your work in this journal}

The International Journal of Women's Health is an international, peer-reviewed open-access journal publishing original research, reports, editorials, reviews and commentaries on all aspects of women's healthcare including gynecology, obstetrics, and breast cancer. The manuscript management system is completely online and includes a very quick and fair peer-review system, which is all easy to use. Visit http://www. dovepress.com/testimonials.php to read real quotes from published authors.

Submit your manuscript here: https://www.dovepress.com/international-journal-of-womens-health-journal 